\title{
Regional Anaesthesia for Breast Surgery
}

\author{
Anjolie Chhabra ${ }^{1}$, Divya Sethi ${ }^{2}$, Abhijit Nair ${ }^{3}$ \\ ${ }^{1}$ Department of Anaesthesia, Pain Medicine and Critical Care, All India Institute of Medical Sciences, New Delhi, India. \\ ${ }^{2}$ Department of Anaesthesia, Employees' State Insurance Cooperation Postgraduate Institute of Medical Sciences and Research, New Delhi, India. \\ ${ }^{3}$ Department of Anaesthesia, Ibra Hospital, North Sharqiya Governorate, Ibra-414, Sultanate of Oman.
}

\section{Innervation of the breast:}

The breast receives innervation mainly from the $2^{\text {nd }}$ to $6^{\text {th }}$ thoracic (T2-6) spinal nerves. The thoracic spinal nerves after emerging from the intervertebral foramina divide into dorsal and ventral ramii [1]. The dorsal ramii provide innervation to the skin and the muscles of the medial back. Each ventral ramus continues anteriorly as an intercostal nerve, accompanied by an intercostal artery and vein lying between the innermost and the internal intercostal muscle along the inferior borders of the respective ribs.

Near the midpoint of the hemithorax corresponding to the midaxillary line, each intercostal nerve gives a lateral cutaneous branch that further divides into an anterior and posterior branch. Sensory supply of lateral aspect of breast is provided by the anterior divisions of the lateral cutaneous branches of T2-T6 intercostal nerves with contributions from T1 and T7 nerves. The intercostal nerves interconnect providing overlapping nerve supply to the breast. The main intercostalnerve continues anteriorly and terminates as an anterior cutaneous branch that further divides into a medial and lateral divisions which provide cutaneous innervation over the sternum and medial part of the breast respectively [2-4] (Figure 1) [5].

The intercostobrachial nerve (T2) mainly provides cutaneous innervation to the axillary tail of the breast, the axilla, and the medial upper arm. The medial cutaneous nerve of the arm (branch of the brachial plexus) may also supply the roof of the axilla and may receive contributions from $\mathrm{T} 1$ and $\mathrm{T} 3$ nerves. The supraclavicular nerves of the cervical plexus provide sensory supply to the infraclavicular or supramammary area $[6,7]$, (Figure 1).

The muscles of chest wall underlying the breast, the pectoralis major (PMM) and pectoralis minor (PmM) are innervated by mixed motor and sensory nerves, the lateral pectoral nerves (LPN) (C5-7, lateral cord) and the medial pectoral nerves (MPN) (C7-T1, medial cord), branches of the brachial plexus. These nerves also possess proprioceptive and nociceptive fibres and thus traction, stretching or muscle spasm of these muscles can lead to dull, aching perioperative pain. In addition, the long thoracic nerve (LTN) (C5-7) and the thoracodorsal nerve (TDN) (C6-8, posterior cord) branches of the brachial plexus innervate the serratus anterior (SAM) and the latissimus dorsi (LD) muscles, that form part of the axilla [8].

Therefore, the breast, axilla and the surrounding tissues are supplied by interconnected network of T2-T6 intercostal nerves, branches of the brachial plexus and the lower branches of the cervical plexus (Figure 1) [5].

\section{Regional anaesthesia blocks used for Breast surgery:}

These blocks will be decribed starting from the older, posteriorly performed blocks to the newer, superficial antero-lateral chest wall blocks for breast surgery.

\section{Thoracic Epidural Anaesthesia (TEA)}

Thoracic epidural block performed at T4 has been used to provide segmental anaesthesia and analgesia extending from C8-T6 for breast surgery.

Advantages of TEA as compared to general anaesthesia (GA) include better perioperative analgesia, lesser postoperative nausea and vomiting (PONV) and shorter length of hospital stay [9]. TEA may be especially useful for providing anaesthesia for bilateral breast surgery or providing analgesia with GA for extensive breast excision and reconstruction surgery i.e. modified radical mastectomy (MRM) with latissmus dorsi (LD ) flap.

Address of Correspondence: Dr. Anjolie Chhabra, Professor, Department of Anaesthesiology, AIIMS, New Delhi, India.

E-mail:anjolie5@hotmail.com

DOI: 10.13107/ijra.2021.v02i01.025 | (C 2021 International Journal of Regional Anaesthesia | Available on www.ijrajournal.com | This is an Open Access article distributed under the terms of the Creative Commons Attribution Non-Commercial License (http://creativecommons.org/licenses/by-nc/3.0) which permits unrestricted non-commercial use, distribution, and reproduction in any medium, provided the original work is properly cited.

How to cite this article: Chhabra A, Sethi D, Nair A | Regional Anaesthesia for Breast surgery | International Journal of Regional Anaesthesia | January-June 2021; 2(1): 40-46. 


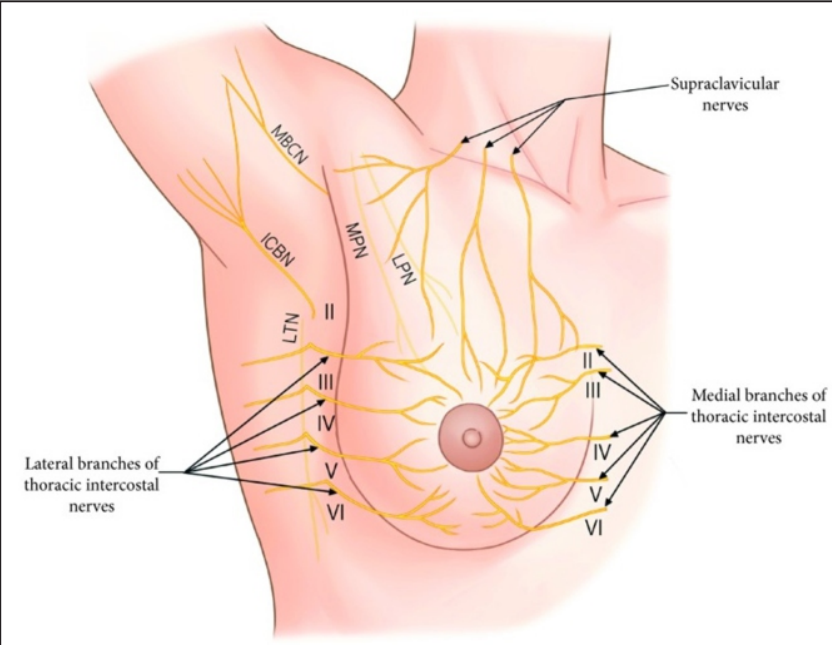

Figure 1: Innervation of the breast.

Reference: Kim DH, Kim S, Kim CS, Lee S, Lee IG, Kim HJ, Lee JH, Jeong SM, Choi KT. Efficacy of Pectoral Nerve Block Type II for Breast-Conserving Surgery and Sentinel Lymph Node Biopsy: A Prospective Randomized Controlled Study. Pain Res Manag. 2018 May $15 ; 2018: 4315931$

Disadvantages of TEA : The invasiveness of the procedure, and the rare but dreaded complication of spinal haematoma has diminished popularity of this technique for breast surgery.

The technical skills required to do the block, a block failure rate of approximately $20 \%$, hypotension due to bilateral sympathetic block have resulted in TEA being replaced by more peripheral regional anaesthesia techniques. There is a single case report of cardiac arrest following TEA for breast surgery [10].

\section{Thoracic Paravertebral block (TPVB)}

The thoracic paravertebral space (TPVS) is a wedge-shaped space, with the base formed by the vertebral bodies, anterolaterally lies the parietal pleura and posteriorly the transverse processes of thoracic vertebrae. Laterally the apex of the TPVS communicates with the intercostal space. There is no defined cranial boundary of the TPVS but the psoas major muscle forms the caudal boundary at L1 level. TPVS consists of fat, dorsal and ventral ramii, intercostal nerves and vessels along with the sympathetic trunk. Local anaesthetic (LA) deposited here results in multidermatomal, ipsilateral, sensory and sympathetic block [11].

Commonly a single injection ipsilateral paravertebral block performed at T3-T4 level with injection of $15-20 \mathrm{ml}$ of LA has been used for providing analgesia for breast surgery as an adjunct to GA [12]. Single injection TPVB has also been used to provide anaesthesia for breast surgery $[13,14]$. However multi-injection ipsilateral TPVB involving injection of $3-5 \mathrm{ml}$ of $0.5 \%$ bupivacaine or ropivacaine at each level from C7/T1-T6 has been more commonly used to provide anaesthesia for breast surgery $[15,16]$.

Different methods of doing the TPVB have been described including the classical anatomical landmark technique described by Eason \& Wyatt in 1979 [17], neurostimulation technique described by Naja et al in 2003 [18], and the ultrasound guided (USG) technique that was subsequently described and is now

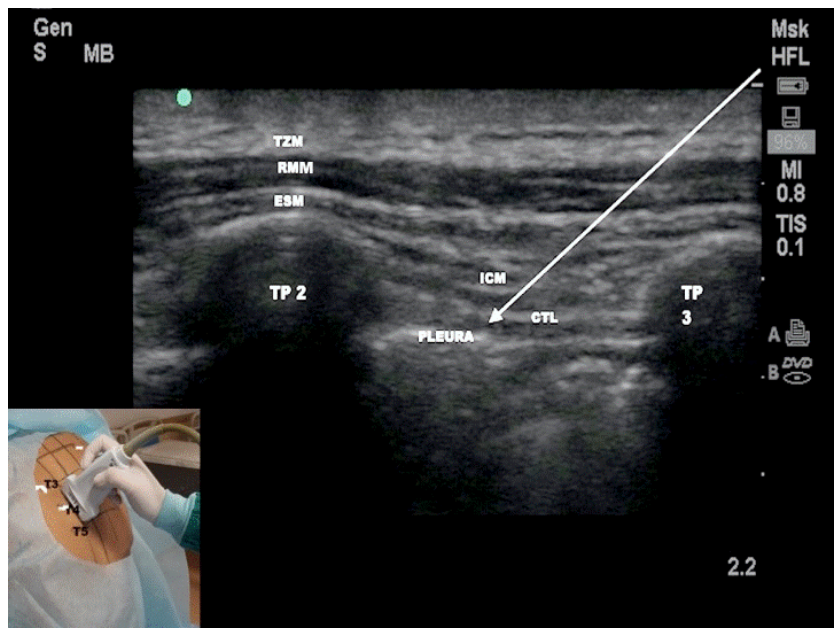

Figure 2: Parasagittal oblique view of USG TPVB

TP- transverse process, CTL - costotransverse ligament, TZM -

Trapezeus muscle, RMM - Rhomboids Major muscle, ESM -

Erector Spinae muscle, ICM - Intercoastal muscle

commonly used for doing a TPVB [19].

Block technique of ultrasound guided (USG) TPVB:

TPVB can be performed with the patient either sitting up (back arched) or lying laterally with the block-side kept non-dependant. The lateral position is usually more comfortable for the patient.

Parasagittal oblique view: This method involves placing the US probe in the para-sagittal plane with a slight lateral tilt at T3-4 vertebral level so as to visualise 2-3 consecutive paravertebral spaces. The block needle is introduced in-plane from caudad to cranially so that the tip pierces the superior costotransverse ligament and lies in the PVS (Figure 2). The TPVS by this approach may be easy to visualise but the block is technically difficult to do because of the steep needle angulation needed as well as the depth of the TPVS. The TPVS is usually at a depth of 4$6 \mathrm{~cm}$. However, the depth further increases at higher vertebral levels (i.e. at T1 compared to T4) and in obese patients. This may require the use of a low frequency curvilinear probe though a high frequency linear array probe is preferred. Use of laser-etched 80$100 \mathrm{~mm} 22 \mathrm{G}$ needle can also improve needle-tip visualisation.

Lateral view: The ultrasound probe is placed transversely over the PVB space allowing a shallower angle of in-plane needle insertion from lateral to medial side. Care should be taken not to advance the needle too medially as it can lead to inadvertent epidural injection or trauma to nerve and vessels emerging from the intervertebral foramina.

Advantages: TPVB includes ipsilateral sensory block with minimal haemodynamic alterations as sensory and sympathetic nerves of only one-side are blocked.

As compared to GA, TPVB provides good perioperative analgesia especially in the first 6 postoperative hours, lesser PONV, and shorter length of hospital stay. 
Disadvantages: The technique has been associated with a low complication rate that includes vascular puncture (1.4\%), pleural puncture $(0.3 \%)$, transient Horner's syndrome $(7.1 \%)$, and epidural block (0.7\%) [20]. Despite the excellent safety profile and many advantages of this block, it is not commonly used for breast surgery because of the technical skills required. The anatomical technique is easier to perform though it has a lower success rate (72-85\%) than the more technically challenging USG PVB which may have $90-100 \%$ success rate [21].

\section{Erector spinae plane block}

The Erector spinae block (ESPB) was first described by Forero et al in 2016 for treatment of thoracic neuropathic pain [22]. The technique involves placing the US probe in the parasagittal plane at T4 level, lateral to the spinous process and identifying the transverse processes and depositing the LA below the erector spinae muscles (ESM) and above the transverse processes. Forero et al surmised that spread of LA through the costotransverse foramina into the TPVS resulted in analgesia extending posteriorly from the paravertebral area to the anterolateral chest wall from T2-T9 dermatomes. This block has been used for providing analgesia for breast surgery as the same dermatomes need to be blocked for breast surgery.

\section{Block Technique}

The block is performed with the patient, sitting up or in the lateral position. A linear, high-frequency USG probe is placed $2.5-3 \mathrm{~cm}$ lateral to the T4 spinous process so as to visualise the thoracic transverse processes and the muscle layers overlying them viz. the trapezius (most superficial), rhomboid major (intermediate), and erector spinae (deepest). A 22-gauge, $80-100 \mathrm{~mm}$ block needle is inserted in plane in cranio-caudal direction to bring the needle-tip to lie below the ESM and above the T4 transverse process. Twenty $\mathrm{ml}$ of LA is then injected visualizing the lifting of the ESM away from the transverse process (Figure 3 ).

Advantages: The ESPB is more superficial (usually at a depth of 3-

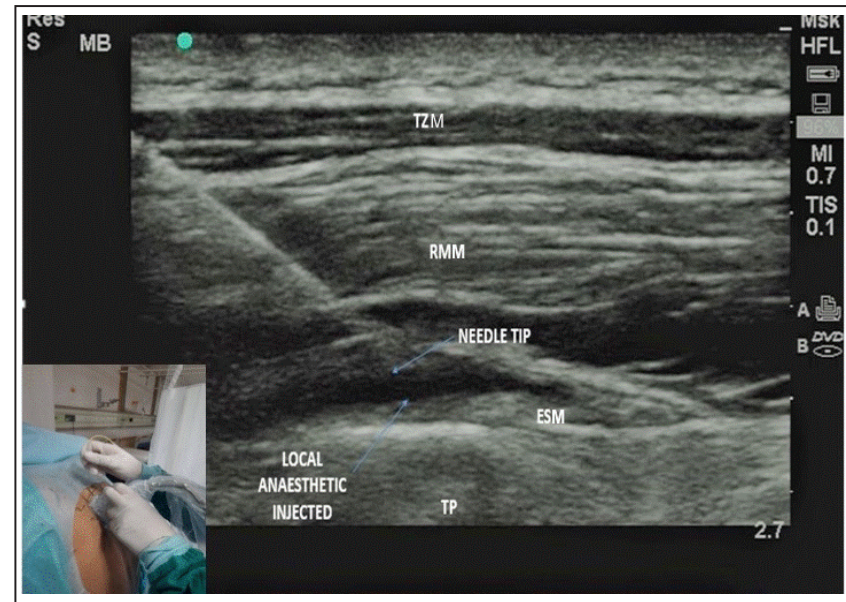

Figure 3: Erector Spinae Plane block (

(TP- transverse process, TZM - Trapezeus muscle, RMM -
$4 \mathrm{~cm}$ ) as compared to the TPVB therefore visualisation of the needle is easier. This block is technically easier to perform as it involves depositing LA over the transverse processes and does not involve needle angulation to reach the TPVS between the transverse processes.

Disadvantage: Though no complications have been reported with this block, potential for pneumothorax, vascular puncture remain if the needle tip is not visualised and inadvertently punctures the pleura. Further, this is a recently introduced block and literature regarding efficacy of this block for breast surgery is still coming in. A recent meta-analysis found that use of the ESPB for patients undergoing MRM resulted in significant reduction in postoperative 24 hours opioid consumption versus no active intervention [23]. The benefit was less marked when ESPB was compared to TPVB or Pecs block [23-25].

A recent study carried out on volunteers has reported that ESPB may produce sensory block of only the posterior chest wall [26]. Therefore, though the ESPB is a superficial, technically simpler USG block, with good safety profile, conclusive evidence supporting the efficacy of this block as compared to other regional blocks for breast surgery is still awaited. This block cannot be used to provide anaesthesia for breast surgery.

\section{Interfascial chest wall blocks}

These include Pecs I, Pecs II and SAP block. Blanco et al described the Pecs I block in 2011 for pain management following breast implant surgery (Table 1). Pecs I involve LA administration between the PMM and PmM in the 2nd intercostal space with USG [27]. In 2012, Blanco et al described the Pecs II block that involved LA administration both above and below the PmM at the level of the $3 \mathrm{rd} / 4 \mathrm{th}$ rib so as to provide analgeisa for wider excision and axillary clearance [28]. In 2013, Blanco et al described the SAP block, for providing analgesia of the T2-6 chest wall [29].

\section{Block Technique}

All these blocks are performed with the patient lying supine with the arm abducted at $90^{\circ}$. The SAP block can be performed the

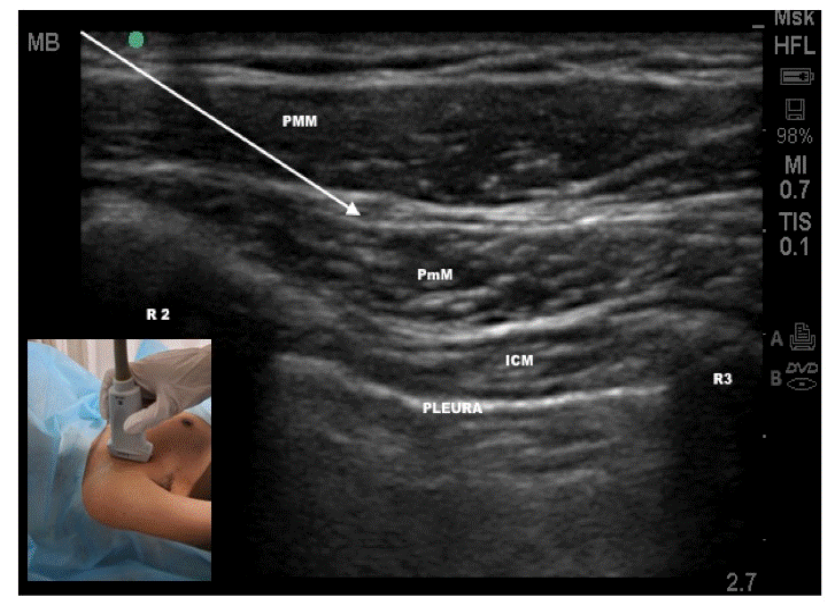

Figure 4: Pecs I block (R2 - second rib, R3- third rib, PMM - Pectoralis Major muscle, PmM- Pectoralis minor muscle) 


\begin{tabular}{|c|c|c|c|c|}
\hline Block & Nerves Blocked & Patient Position & Injection Site & Indications \\
\hline Pecs I & $\begin{array}{l}\text { Lateral }(\mathrm{C} 5,6,7) \text { and Medial } \\
(\mathrm{C} 8, \mathrm{~T} 1) \text { Pectoral Nerve }\end{array}$ & $\begin{array}{c}\text { Supine with arm by the side or } \\
\text { abducted } 90 \text { degree }\end{array}$ & $\begin{array}{l}\text { The interfascial plane between PMM and } \\
\text { PmM in the infraclavicular region at } 3^{\text {rd }} \text { rib. } \\
\text { LA volume: } 0.2 \mathrm{ml} / \mathrm{kg} \\
\text { The spread of LA is seen in the } \\
\text { compartment between pectoral and } \\
\text { clavipectoral fascia }\end{array}$ & $\begin{array}{l}\text { Cosmetic breast surgery- Placement of } \\
\text { breast expander or subpectoral } \\
\text { prosthesis. } \\
\text { Others- Insertion of pacemakers, chemo- } \\
\text { ports. }\end{array}$ \\
\hline Pecs II & $\begin{array}{c}\text { Lateral }(\mathrm{C} 5,6,7) \text { and Medial } \\
(\mathrm{C} 8, \mathrm{~T} 1) \text { and Pectoral Nerve } \\
\text { Intercostobrachial }(\mathrm{T} 2) \\
\text { Lateral cutaneous branches } \\
\text { Intercostal Nerves (T2-T6) } \\
\text { Long thoracic nerve (C5, 6, 7) } \\
\text { Thoracodorsal Nerve } \\
(\mathrm{C} 6,7,8)\end{array}$ & $\begin{array}{l}\text { Supine with arm by the side or } \\
\text { abducted } 90 \text { degree }\end{array}$ & \begin{tabular}{|c|} 
First injection point - same as Pecs 1 \\
Second injection point- Interfascial plane \\
between PmM and SAM at the anterior \\
axillary line at 4 th rib \\
Local anaesthetic volume: $0.4 \mathrm{ml} / \mathrm{kg}$. (For \\
$30 \mathrm{ml}$ total volume - $10 \mathrm{ml}$ at Pecs 1 and 20 \\
$\mathrm{ml}$ at Pecs 2 ) \\
The spread of LA is seen in the \\
compartment between clavipectoral fascia \\
and SAM
\end{tabular} & $\begin{array}{l}\text { Breast cancer surgery: wide local } \\
\text { excision, radical mastectomy, axillary } \\
\text { clearance, sentinel node biopsy }\end{array}$ \\
\hline SAP Block & $\begin{array}{c}\text { Intercostobrachial (T2) } \\
\text { Lateral cutaneous branches } \\
\text { of intercostal nerves (T2-T9) } \\
\text { Long thoracic nerve }(\mathrm{C} 5,6,7) \\
\text { Thoracodorsal Nerve } \\
(\mathrm{C} 6,7,8)\end{array}$ & $\begin{array}{c}\text { Supine or } \\
\text { Semi- lateral with the arm } \\
\text { abducted } 90 \text { degree }\end{array}$ & $\begin{array}{l}\text { Superficial or deep to SAM at the } \\
\text { midaxillary line at } 5^{\text {th }} \text { rib } \\
\text { Local anaesthetic volume: } 0.2-0.4 \mathrm{ml} / \mathrm{kg} \\
\text { The spread of LA is seen in the } \\
\text { compartment between SAM and } \\
\text { extrathoracic fascia }\end{array}$ & $\begin{array}{c}\text { Reconstructive breast and cosmetic } \\
\text { breast surgery (latissimus dorsi flap), } \\
\text { axillary clearance, } \\
\text { sentinel lymph node biopsy. } \\
\text { Others- Surgery involving incision on the } \\
\text { anterior lateral chest wall, placement of } \\
\text { chest drain, anterior thoracotomy, } \\
\text { analgesia in rib fracture }\end{array}$ \\
\hline
\end{tabular}

lateral position with the arm extended over the head. A linear high-frequency US (ultrasound) probe and 80-100 mm block needles can be used.

\section{Pecs I block}

The USG probe is placed in a sagittal plane in the infraclavicular fossa along the mid-clavicular line. The second rib is identified as caudad and posterior to the axillary vessels. The caudad end of the probe is rotated slightly laterally towards the deltopectoral groove to identify the pectoral branch of thoraco acromion artery (TCA), the PMM, PmM, and underlying $3^{\text {rd }}$ rib. The block needle is inserted in-plane in cephalic-medial to the caudal-lateral direction and LA is injected visualizing the separation of the plane between PMM and PmM (Figure 4).

Pecs II block involves the Pecs I block as well as a second injection between the PmM and the SAM. The US probe is slid further caudally and laterally along the deltopectoral groove towards the anterior axillary to visualise the SAM below the PmM at the level of $3^{\text {rd }} / 4^{\text {th }}$ rib. The block needle is inserted in-plane in cephalicmedial to the caudal-lateral direction to reach the fascial plane between PmM and SAM and LA is injected (Figure 4).

\section{Serratus anterior plane (SAP) Block}

The US probe is slid caudally and laterally along the deltopectoral groove towards the mid-axillary line at the level of $5^{\text {th }}$ rib. The latissimus dorsi muscle (LDM) and SAM are identified overlying the 5 th rib. The thoracodorsal artery is also identified in this fascial plane between LDM and SAM.

Two techniques of SAP block have been described, the superficial and deep SAP block. In superficial SAPB, the needle tip is either directed to lie in the plane between the LDM and SAM muscles and LA is injected separating these muscles. Alternately, in deep SAP block the LA is injected below SAM lifting it away from the rib (Figure 6). Superficial SAP block in a volunteer study demonstrated more extensive sensory loss (T2-T9) than the deep SAP block (T2-T6) [29]. Duration of sensory and motor blocks also lasted for longer after the superficial SAP block. However, the easily identified landmarks make the deep SAP block easier to perform though the LTN may not get blocked if LA is injected below the SAM. Further clinical randomised controlled trials need to be conducted to corroborate results of the volunteer study.

Advantages: The Pecs I, II and SAP blocks are superficial USG interfascial plane blocks that are simple alternative to both TPVB and TEA for blocking the intercostal nerves and can provide analgesia of the anterolateral chest wall and the breast. The Pecs II block that also involves the Pecs I block, can block the upper intercostal nerves, the LPN, the MPN as well as the LTN and TDN, all branches of the brachial plexus that supply the muscles underying the breast and axilla.

A study comparing Pecs II block to PVB at T2 level as adjuncts to GA for analgesia found that the Pecs block may be more effective for providing analgesia following MRM than the TPVB [30]. The authors opined that this may be because the Pecs block, in addition to T1-T3 intercostal nerves, also anaesthetises MPN, LPN, LTN and TDN.

Disadvantage: Though Pecs I, II and SAP blocks are superficial blocks performed under US guidance, needle proximity to pleura raises concerns of pneumothorax, vascular puncture if adequate care is not taken.

In addition, the area medial and cranial to the mammary area may be spared with these blocks. 
Though the Pecs I and II blocks and SAP blocks in addition to intercostal nerves may anaesthetise MPN, LPN, LTN and TDN nerves that have afferent $\mathrm{C}$ fibres conducting pain from the muscles underlying the breast and forming the axilla it is still debatable whether these nerves need to be blocked for breast surgery. Some authors argue that anaesthesia for breast surgery can be provided by TEA or TPVB and both techniques block only the T2-6 intercostal nerves and not branches of the brachial plexus [31]. However, even with a successful T2-T6 TPVB block, for breast surgery involving axillary dissection, patients can have pain requiring LA infiltration in the surgical site or supplementation with opioids. This may be because of overlapping nerve supply by supraclavicular branches (C3-4) of the cervical plexus and provided by branches of brachial plexus i.e. the medial cutaneous branch of the arm in the axilla. Therefore, further studies need to be conducted though the Pecs block may be used as an adjunct to TPVB for breast surgery involving axillary dissection.

\section{Pecto-Intercostal Fascial Block (PIFB) and Transversus Thoracic Plane Block (TTPB)}

PIFB and TTPB blocks provide sensory anaesthesia to the medial side of the breast by blocking the anterior cutaneous branches of T2-6 intercostal nerves. The US probe is placed in sagittal orientation in the parasternal region between $3 \mathrm{rd}$ and 4 th ribs. For the PIFB the probe is kept $3-4 \mathrm{~cm}$ lateral to the sternal border and $20 \mathrm{ml}$ of dilute LA injected between the PMM and the external ICM (intercostal muscle) (Figure 6) [31, 32]. In TTPB, the ultrasound probe is placed more medially on the lateral border of the sternum and10-20 $\mathrm{ml}$ of LA is deposited between internal ICM (and the TTM (transversus thoracic muscle) [32,33].

Advantage: Both these blocks anaesthetise the medial side of the breast which may be spared with SAP or Pecs blocks. Therefore, if extensive dissection of the medial side of the breast is needed PIFB or TTPB may need to be combined with the Pecs or SAP block to provide analgesia [34] (Figure 7).

Disadvantage: In the TTPB the needle is very close to the pleura, only separated by the thin TTM (Figure 6). In addition, the internal thoracic artery also travels in this plane just lateral to the sternum. The PIFB therefore an easier and a safer approach than the TTPB $[31,32]$.

\section{Choice of the Regional anaesthesia technique:}

The choice of regional anaesthesia for breast surgery should be based on:

1. Whether regional anaesthesia technique is to be used for providing anaesthesia or analgesia.

Surgical anaesthesia for breast surgery can be provided either by thoracic epidural anaesthesia (TEA), or by thoracic paravertebral block (TPVB). These blocks can also provide perioperative analgesia. All interfascial chest wall blocks i.e. the Pecs block, serratus anterior plane (SAP) block, the erector spinae plane block (ESPB), the thoracic transversus plane block (TTPB) and pectointercostal fascial block (PIFB) are used primarily for providing analgesia for breast surgery in combination with general anaesthesia (GA).

2. The extent and type of breast surgery:

a. For lumpectomy, simple mastectomy i.e. breast surgery without axillary dissection mainly the T1-6 intercostal nerves need to be blocked. Analgesia can be provided using TEA, ipsilateral TPVB (single injection at T3-T4 level), ESP, SAP block or the Pecs II block. At times the SAP block performed in the midaxillary line 5th intercostal space may miss the lateral cutaneous nerve if the block is performed distal to where the nerve branches off. Therefore, blocks performed posteriorly and more proximal to the neuraxis (e.g. the ESPB) may provide more effective analgesia.

b. In addition to mastectomy, breast cancer surgery may also involve sentinel lymph node biopsy or axillary lymph node clearance (modified radical mastectomy or MRM) or pectoralis major excision (radical mastectomy) or all of the above with breast reconstruction. The more extensive the surgery, greater the need for perioperative analgesia to prevent chronic post surgical pain. c. The Pecs blocks provide analgesia for the anterior part of the upper chest wall and a window to access the axilla, the nerves supplying the pectoral muscles, (LPN, MPN), the LTN and TD

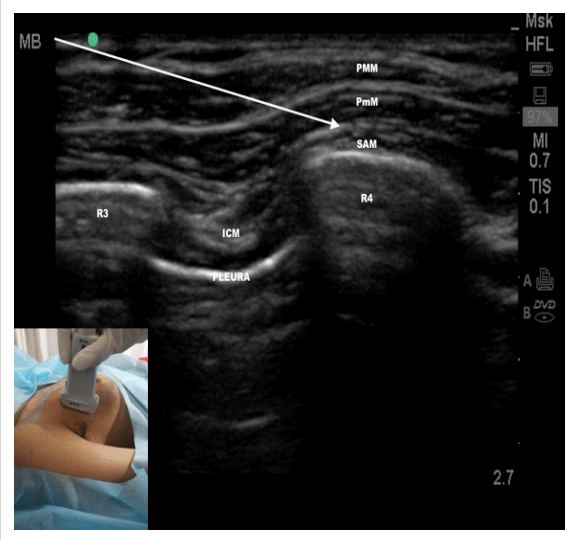

Figure 5: Pecs II block.

R3- third rib, R4 - fourth rib, PMM - Pectoralis Major muscle, PmM- Pectoralis minor muscle, SAM - Serratus Anterior muscle.

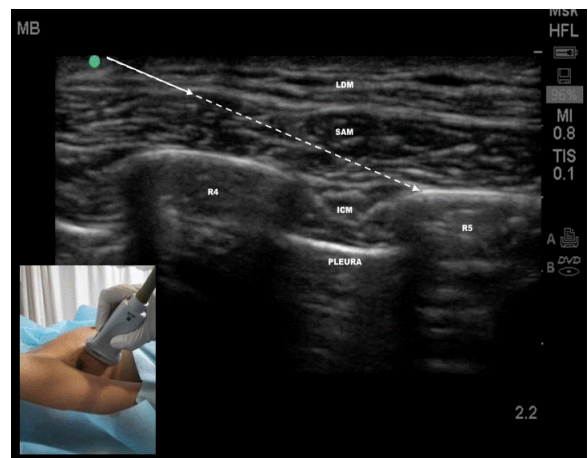

Figure 6: Serratus Anterior Plane block. Solid arrow represents insertion of needle for superficial SAP block; dotted arrow represents insertion of needle for deep SAP block. TTPB R4 - fourth rib, R5 - fifth rib, LDM- Lattismus dorsi muscle, SAM - Serratus Anterior muscle, ICM - Intercoastal muscle.

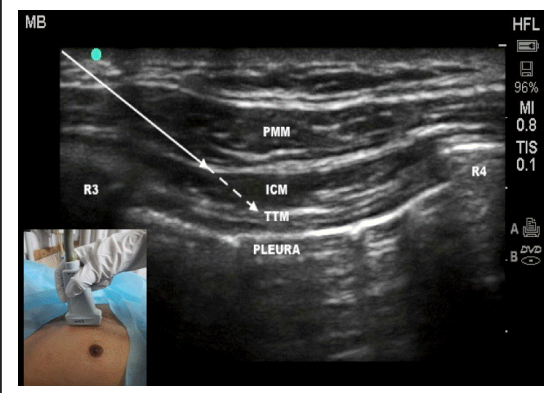

Figure 7: Pecto-Intercostal Fascial Block (PIFB) and Transversus Thoracic Plane Block (TTPB)

Solid arrow represents insertion of needle for PIFB; dotted arrow represents insertion of needle for TTPBR3- third rib, R4 - fourth rib, PMM - Pectoralis Major muscle, ICM Intercoastal muscle, TTM - Transverse thoraci muscle 
nerves. Therefore, Pecs block have been found to provide effective analgesia for cosmetic breast surgery involving sub-pectoral implant insertion. They have also been used as adjuncts to the TPVB together with supraclavicular subcutaneous local anaesthetic (LA) infiltration for providing analgesia following MRM (Table 1).

3. Blocks should be tailored according to the skill of the anaesthesiologists, equipment available (nerve stimulator e.g., ultrasound machine etc.) as well the facilities available for monitoring and follow up. Patient consent, absence of inflammation, normal coagulation are prerequisites for performing any block.
To conclude, innervation of the breast is complex with main nerve supply being provided by T2-T6 intercostal nerves. To produce stand alone anaesthesia, TEA or TPVB anaesthetising these nerves can be used. To provide analgesia more superficial USG plane blocks can be used such as the ESPB, SAP block, or the Pecs blocks. For surgery involving axillary dissection in addition to blocking the intercostal nerves LA infiltration or opioid supplmentation may be required. Similarly, for dissection extending upto the supramammary or infraclavicular area, subcutaneous LA infiltration above the clavicle may be needed to block the supraclavicular branches of the cervical plexus.

\section{References}

1. Wijayasinghe N, Andersen KG, Kehlet $H$. Neural blockade for persistent pain after breast cancer surgery. Reg Anesth Pain Med. 2014;39:272-8.

2. Woodworth GE, Ivie RMJ, Nelson SM, Walker CM, Maniker RB. Perioperative Breast Analgesia: A Qualitative Review of Anatomy and Regional Techniques. RegAnesth Pain Med. 2017; 42:609-31.

3. Cheng GS, Ilfeld BM. An Evidence-Based Review of the Efficacy of Perioperative Analgesic Techniques for Breast Cancer-Related Surgery. Pain Med.2017Jul 1; 18:1344-65.

4. Cheng GS, Ilfeld BM. A review of postoperative analgesia for breast cancer surgery. Pain Manag. 2016; 6:603-18.

5. Kim DH, Kim S, Kim CS, Lee S, Lee IG, Kim HJ, Lee JH, Jeong SM, Choi KT. Efficacy of Pectoral Nerve Block Type II for Breast-Conserving Surgery and Sentinel Lymph Node Biopsy: A Prospective Randomized Controlled Study. Pain Res Manag. 2018 May 15;2018:4315931.

6. Wisotzky EM, Saini V, Kao C. Ultrasound-Guided Intercostobrachial Nerve Block for Intercostobrachial Neuralgia in Breast Cancer Patients: A Case Series. PMR. 2016; 8:273-7.

7. Sarhadi NS, Shaw-Dunn J, Soutar DS. Nerve supply of the breast with special reference to the nipple and areola: Sir Astley Cooper revisited. Clin Anat. 1997; 10:283-7. Nair AS. Cutaneous innervations encountered during mastectomy: A perplexing circuitry. Indian J Anaesth. 2017; 61:1026-27.

8. Nair AS. Cutaneous innervations encountered during mastectomy: A perplexing circuitry. Indian J Anaesth. 2017; 61:1026-27.

9. Ravi PR, Jaiswal P. Thoracic epidural analgesia for breast oncological procedures: A better alternative to general anesthesia.J Mar Med Soc 2017; 19: 91-5.

10. Chan KK, Welch KJ. Cardiac arrest during segmental thoracic epidural anesthesia. Anesthesiology. 1997;86: 503-5.

11. Karmakar MK. Thoracic paravertebral block. Anesthesiology. 2001;95:771-780.

12. Kairaluoma PM, Bachmann MS, Rosenberg PH, Pere PJ. Single injection paravertebral block before general anaesthesia enhances analgesia after breast cancer surgery with and without associated lymph node biopsy. Anesthesia and Analgesia 2004;99(6):1837-43.

13. Pusch F, Freitag H, Weinstabl C, Obwegeser R, Huber E, Wildling E. Single-injection paravertebral block compared to general anaesthesia in breast surgery. Acta Anaesthesiologica Scandinavica 1999;43(7):770-4.

14. Terheggen MA, Wille F, Borel Rinkes IH, Ionescu TI, Knape JT.
Paravertebral blockade for minor breast surgery. Anesthesia \& Analgesia 2002;94(2):355-9.

15. Greengrass R, O'Brien F, Lyerly K, Hardman D, Gleason D, D'Ercole F, et al. Paravertebral block for breast cancer surgery. Canadian Journal of Anaesthesia 1996;43(8):858-61.

16. Abdallah FW, Morgan PJ, Cil T, McNaught A, Escallon JM, Semple JL, et al. Ultrasound-guided multilevel paravertebral blocks and total intravenous anesthesia improve the quality of recovery after ambulatory breast tumor resection. Anesthesiology 2014;120(3):703-13.

17. Eason MJ, Wyatt R. Paravertebral thoracic block-a reappraisal. Anaesthesia 1979;34: 638-42.

18. Naja MZ, Ziade MF, Lonnqvist PA. Nerve stimulator guided paravertebral blockade versus general anaesthesia for breast surgery: a prospective randomized trial. Eur JAnaesthesiology 2003;20: 897-903.

19. Krediet AC, Moayeri N, van Geffen GJ, Bruhn J, Renes S, Bigeleisen PE, et al. Different Approaches to Ultrasound-guided Thoracic Paravertebral Block: An Illustrated Review. Anesthesiology. 2015;123:459-74.

20. Chhabra A, Roy Chowdhury A, Prabhakar H, Subramaniam R, Arora M Kumar, Srivastava A, Kalaivani M. Paravertebral anaesthesia with or without sedation versus general anaesthesia for women undergoing breast cancer surgery. Cochrane Database of Systematic Reviews 2021, Issue 2. Art. No.: CD012968

21. Lönnqvist PA, MacKenzie J, Soni AK, Conacher ID. Paravertebral blockade. Failure rate and complications. Anaesthesia 1995;50: 813-5.

22. Patnaik R, Chhabra A, Subramaniam R, Arora MK, Goswami D, Srivastava A, et al. A Randomized Controlled Trial. Comparison of Paravertebral Block by Anatomic Landmark Technique to UltrasoundGuided Paravertebral Block for Breast Surgery Anesthesia. Reg Anesth Pain Med 2018;43: 385-90.

23. Forero M, Adhikary SD, Lopez H, Tsui C, Chin KJ. The erector spinae plane block: a novel analgesic technique in thoracic neuropathic pain. Reg Anaesth Pain Med 2016;41:621-7.

24. Huang W, Wang W, Xie W, Chen Z, Liu Y. Erector spinae plane block for postoperative analgesia in breast and thoracic surgery: A systematic review and meta-analysis.JClin Anesth. 2020;66:109900.

25. Altıparmak B, Korkmaz Toker M, Uysal Aİ, Turan M, GümüşDemirbilek $S$. Comparison of the effects of modified pectoral nerve block and erector spinae plane block on postoperative opioid consumption and pain scores of patients after radical mastectomy surgery: A prospective, randomized, controlled trial.J 
Clin Anesth. 2019;54: 61-5.

26. Gürkan Y, Aksu C, Kuş A, Yörükoğlu UH. Erector spinae plane block and thoracic paravertebral block for breast surgery compared to IV-morphine: a randomized controlled trial.J Clin Anesth. 2020; 59: 84-8.

27. Zhang J, He Y, Wang S, Chen Z, Zhang Y, Gao Y, Wang Q, Xia Y, Papadimos TJ, Zhou R. The erector spinae plane block causes only cutaneous sensory loss on ipsilateral posterior thorax: a prospective observational volunteer study. BMC anesthesiology.2020 Dec;20:1-8.

28. Blanco R. The 'pecs block': a novel technique for providing analgesia after breast surgery. Anaesthesia.2011;66:847-8.

29. Blanco R, Fajardo M, Parras Maldonado T. Ultrasound description of Pecs II (modified Pecs I): a novel approach to breast surgery. Rev Esp Anestesiol Reanim.2012;59:470-5.

30. Blanco R, Parras T, McDonnell JG, Prats-Galino A. Serratus plane block: a novel ultrasound-guided thoracic wall nerve block. Anaesthesia. 2013;68:1107-13.
31. Kulhari S, Bharti N, Bala I, Arora S, Singh G. Efficacy of pectoral nerve block versus thoracic paravertebral block for postoperative analgesia after radical mastectomy: a randomized controlled trial. $\mathrm{Br} J$ Anaesth. 2016;117:382-86.

32. Franco CD, Inozemtsev K. Reg Anesth Pain Med. 2020;45:151-154.

33. George R, Dahl K, Blair DHJ. How I Do It: Transversus Thoracic Plane and Pecto-Intercostal Fascial Block. ASRA NEWS. Available at https://www.asra.com/asra-news/article/250/how-i-do-it-transversusthoracic-plane-a and Pecto-Intercostal Fascial Block. Last accessed on December 15, 2020.

34. Murata H, Hida K, Hara T. Transverse thoracic muscle plane block. Reg Anesth Pain Med.2016;41:411-12.

35. Ueshima H, Otake H. Addition of transversus thoracic muscle plane block to pectoral nerves block provides more effective perioperative pain relief than pectoral nerves block alone for breast cancer surgery. $\mathrm{Br} J$ Anaesth. 2017;118:439-43

Conflict of Interest: Nil

Source of Support: None

Acknowledgment: Figures 2-7, Courtsey Dr. Divya Sethi

46 | International Journal of Regional Anaesthesia | Volume 2 | Issue 1 | January-June 2021 | Page 40-46 